\title{
Regulatory Mechanisms of Exoribonuclease PNPase and Regulatory Small RNA on T3SS of Dickeya dadantii
}

\author{
Quan Zeng, ${ }^{1}$ A. Mark Ibekwe, ${ }^{2}$ Eulandria Biddle, ${ }^{1}$ and Ching-Hong Yang ${ }^{1}$ \\ ${ }^{1}$ Department of Biological Sciences, University of Wisconsin-Milwaukee 53211, U.S.A.; ${ }^{2}$ United States Department of \\ Agriculture-Agricultural Research Service, U. S. Salinity Lab, Riverside, CA 92507, U.S.A.
}

Submitted 15 March 2010. Accepted 21 May 2010.

The type III secretion system (T3SS) is an essential virulence factor for many bacterial pathogens. Polynucleotide phosphorylase (PNPase) is one of the major exoribonucleases in bacteria and plays important roles in mRNA degradation, tRNA processing, and small RNA (sRNA) turnover. In this study, we showed that PNPase downregulates the transcription of T3SS structural and effector genes of the phytopathogenic bacterium Dickeya dadantii. This negative regulation of T3SS by PNPase occurs by repressing the expression of $h r p L$, encoding a master regulator of T3SS in D. dadantii. By reducing rpoN mRNA stability, PNPase downregulates the transcription of $h r p L$, which leads to a reduction in T3SS gene expression. Moreover, we have found that PNPase downregulates T3SS by decreasing hrpL mRNA stability. RsmB, a regulatory SRNA, enhances hrpL mRNA stability in $D$. dadantii. Our results suggest that PNPase decreases the amount of functional RsmB transcripts that could result in reduction of $h r p L$ mRNA stability. In addition, bistable gene expression (differential expression of a single gene that creates two distinct subpopulations) of $h r p A, h r p N$, and $d s p E$ was observed in $D$. dadantii under in vitro conditions. Although PNPase regulates the proportion of cells in the high state and the low state of T3SS gene expression, it appears that PNPase is not the key switch that triggers the bistable expression patterns of T3SS genes.

Polynucleotide phosphorylase (PNPase), encoded by pnp, is widespread in prokaryotes as well as in the chloroplasts and mitochondria of eukaryotes. It is one of the most important exoribonucleases in the cell (Kinscherf and Apirion 1975; Kudla et al. 1996; Leszczyniecka et al. 2002) and has both $3^{\prime}$ to 5 ' exoribonuclease activity and 3 '-terminal oligonucleotide polymerase activity (Mohanty and Kushner 2000). Based on sequence homology, PNPase in most prokaryotes contains four conserved functional domains. An S1 domain and a $\mathrm{KH}$ domain are located at the C-terminus of PNPase, both of which are critical for the RNA binding and substrate recognition activity of PNPase (Stickney et al. 2005; Amblar et al. 2007). Two RNase PH-like domains are located at the $\mathrm{N}$ terminus, which are responsible for PNPase's phosphate-dependent exonuclease activity and its RNA polyadenylation activity (Zuo and Deutscher 2001).

Corresponding author. Ching-Hong Yang; Telephone: 414-229-6331; Fax: 414-229-3926; E-mail: chyang@uwm.edu

* The $\boldsymbol{e}$-Xtra logo stands for "electronic extra" and indicates that four supplementary figures are published online.
PNPase is involved in mRNA degradation, tRNA processing and degradation, small RNA (sRNA) turnover, and the addition of heteropolymeric tails to some RNAs (Kinscherf and Apirion 1975; Li and Deutscher 1994; Mohanty and Kushner 2000; Oussenko et al. 2005; Viegas et al. 2007). In bacteria, RNA degradation usually occurs in two stages. During the first stage, full-length RNA is cleaved into short fragments of RNA decay intermediates by endoribonucleases such as RNase E, RNase G, RNase III, and RNase P (Mackie 1998; Kushner 2002; Deutscher 2006). Following the initial endonucleolytic attack, these decay intermediates undergo complete breakdown into mononucleotides by exoribonucleases and oligoribonucleases. PNPase, along with other exoribonucleases such as RNase II and RNase R, contribute to the second stage of the RNA degradation process through its $3^{\prime}$ to $5^{\prime}$ exonuclease activity (Donovan and Kushner 1986; Deutscher 2006). In addition to exonuclease activity, PNPase can function as a poly(A) polymerase by adding nucleotides to an existing poly(A) tail of mRNA transcribed by PAP1 (Kinscherf and Apirion 1975; Li and Deutscher 1994; Mohanty and Kushner 2000; Oussenko et al. 2005; Viegas et al. 2007). The heteropolymeric tails synthesized by PNPase may further enhance the degradation of mRNA intermediates by disrupting the secondary structure at the $3^{\prime}$ termini of the RNA.

Several cellular metabolic processes are regulated by PNPase through its post-transcriptional control of mRNA. Yamanaka and Inouye (2001) have demonstrated that PNPasemediated RNA degradation is required for the regulation of the cold-shock response in Escherichia coli. They discovered that a number of specific mRNAs induced by cold shock are degraded by PNPase at the end of the acclimation phase (Yamanaka and Inouye 2001; Polissi et al. 2003). In addition, PNPase regulates cellular responses to environmental changes by controlling regulatory sRNA turnover. Viegas and associates (2007) showed that PNPase is important for the decay of four regulatory sRNAs: CsrB, CsrC, MicA, and SraL. Andrade and Arraiano (2008) also illustrated that PNPase is important in controlling the amount of regulatory sRNA required for the expression of some outer-membrane proteins. Together, these reports demonstrate that, in addition to its role in the general degradation of RNA, PNPase-controlled RNA degradation can also be specific.

Dickeya dadantii 3937 (formerly Erwinia chrysanthemi 3937) is a gram-negative phytopathogenic bacterium that causes soft rot, wilt, and blight diseases on a wide range of plants. $D$. $d a$ dantii possesses a type III secretion system (T3SS), a major virulence factor in many gram-negative plant and animal pathogens (Alfano and Collmer 1997, 2004; Galan and Collmer 1999; Hueck 1998). The T3SS of $D$. dadantii is encoded by several structural and effector genes, such as $h r p A, h r p N$, and $d s p E$, 
which encode a T3SS pilus, harpin, and effector, respectively. The transcription of T3SS structural and effector genes is controlled by the master regulator and alternative $\sigma$ factor, $\mathrm{HrpL}$ (Tang et al. 2006). $h r p L$ expression is activated by $\operatorname{RpoN}\left(\sigma^{54}\right)$ in conjunction with HrpS, an NtrC family enhancer protein (Yap et al. 2005; Tang et al. 2006). The transcription of hrpS is upregulated by a two-component signal transduction system (TCSS), HrpX/HrpY (Tang et al. 2006). In addition to regulation at the transcriptional level, the expression of $h r p L$ is also controlled at the post-transcriptional level by the RsmA/RsmB pair (Yang et al. 2008a,b). RsmA (repressor of stationary phase metabolites) is a sRNA-binding protein that binds to and promotes the degradation of $h r p L$ mRNA. RsmB is a sRNA molecule that binds to RsmA and neutralizes its degradation effect on $h r p L$ mRNA (Liu et al. 1998). The expression of RsmB is upregulated by another TCSS, GacS/GacA (Yang et al. 2008b).

Although the regulatory mechanism is unclear, microarray analysis of Salmonella enterica showed that PNPase affects mRNA levels of virulence genes located in Salmonella pathogenicity islands 1 and 2 that encode a syringe-like organelle of the T3SS (Clements et al. 2002). In Yersinia pseudotuberculosis and $Y$. pestis, PNPase is required for the optimal function of T3SS (Rosenzweig et al. 2005, 2007; Rosenzweig and Schesser 2007). In this report, we demonstrate that the PNPase of $D$. dadantii 3937 reduces mRNA stability of a key T3SS regulator, RpoN. RpoN instability results in a repressive effect on $h r p L$ which ultimately downregulates the transcription of T3SS genes. Our results also suggest a role for PNPase in the turnover of an untranslated regulatory sRNA, RsmB, which may further affect the expression of T3SS genes in D. dadantii. Finally, bistable expression patterns of T3SS structural and effector genes were observed in $D$. dadantii 3937 and the regulatory effect of PNPase on the bistable expression of T3SS genes was examined.

\section{RESULTS}

\section{PNPase downregulates the transcription of T3SS structural and effector genes.}

The effects of PNPase were analyzed on three representative T3SS structural and effector genes: $h r p A, h r p N$, and $d s p E$. A pnp deletion mutant (Ech152) (Table 1) was constructed and the mRNA levels and promoter activities of $h r p A, h r p N$, and $d s p E$ were examined in Ech152 and the wild-type strain, $D$. dadantii 3937. Northern blot analysis revealed an increase in hrpA mRNA in Ech152 (Fig. 1A). The hrpA mRNA was restored to the wild-type level upon complementation of Ech152 with pML1231 (Fig. 1A). The mRNA levels of $h r p N$, and $d s p E$, along with $h r p A$, were also measured by real-time polymerase chain reaction (PCR) in D. dadantii 3937 and Ech152. Compared with the wild type, significantly higher amounts of hrpA (relative expression ratio $16.44, P=0.002$ ), $h r p N$ (relative expression ratio $48.39, P \leq 0.001$ ), and $d s p E$ (relative expression ratio $34.51, P \leq 0.001)$ mRNA were observed in Ech152 (Fig. 1B). Promoter activities of $h r p A, h r p N$, and $d s p E$ were also examined in D. dadantii 3937 and Ech152 carrying plasmids with promoter green fluorescence protein (GFP) transcriptional fusions phrpA, phrpN, and pdspE, respectively. Higher promoter activities of $h r p A, h r p N$, and $d s p E$ were observed in Ech152 by a fluorescence-activated cell sorter (FACS) (Fig. 1C). These results strongly suggest that PNPase downregulates the transcription of $h r p A, h r p N$, and $d s p E$.

\section{PNPase downregulates $h r p L$ transcription by affecting rpoN mRNA stability.}

In $D$. dadantii 3937, $\mathrm{HrpL}$ is a master regulator of genes encoding T3SS structural and effector proteins. Therefore, down- regulation of $h r p L$ transcription would lead to a reduction in the expression of $h r p A, h r p N$, and $d s p E$. To investigate the regulatory effect of PNPase on $h r p L$, both the mRNA level and promoter activity of $h r p L$ were examined in the wild type and Ech152. Compared with the wild-type strain, an increase in both hrpL promoter activity and mRNA level was observed in Ech152 (Fig. 2A and B). This indicates that the transcription of $h r p L$ is downregulated by PNPase, which explains the decrease in $h r p A$, $h r p N$, and $d s p E$ transcription. Because $h r p L$ is upregulated by RpoN and HrpS at the transcriptional level (Chatterjee et al. 2002; Yap et al. 2005), the mRNA levels of $r p o N$ and $h r p S$ in D. dadantii 3937 and Ech152 were also examined. Compared with $D$. dadantii 3937, an 11-fold increase of rpoN mRNA levels $(P \leq 0.001)$ was observed in the pnp mutant (Fig. 2B). No significant difference in $h r p S$ mRNA level $(P>0.05)$ was observed between the wild-type strain and Ech152 (Fig. 2B). This indicates that the increase in $h r p L$ promoter activity observed in Ech152 is due to the increased amount of rpoN mRNA. The rpoN mRNA stability was then tested in $D$. dadantii 3937 and Ech152 (Fig. 3A). Compared with the wild-type strain, the rpoN mRNA decay rate was much slower in Ech152 (rpoN mRNA half-life: wild type, $8.64 \mathrm{~min}$; Ech152, $241.38 \mathrm{~min}$ ). Together, these results demonstrate that PNPase functions to reduce rpoN mRNA stability which, in turn, has negative effects on $h r p L$ transcription and, consequently, on the transcription of the T3SS structural and effector genes.

\section{PNPase affects $h r p L$ mRNA stability and RsmB sRNA transcript pattern.}

In $D$. dadantii 3937, in addition to the transcriptional regulation by RpoN and HrpS, the $h r p L$ mRNA level is also controlled through the GacS-GacA-RsmB-RsmA-HrpL post-transcriptional regulatory pathway (Yang et al. 2008a,b). To determine whether PNPase controls $h r p L$ at the post-transcriptional level, an RNA decay assay was performed to examine the $h r p L$ mRNA stability in D. dadantii 3937 and Ech152 (Fig. 3B). A reduction in the $h r p L$ mRNA decay rate ( $h r p L$ mRNA half-life: wild type, $9.16 \mathrm{~min}$; Ech152, $14.46 \mathrm{~min}$ ) was observed in Ech152 compared with $D$. dadantii 3937, suggesting that PNPase is involved in the post-transcriptional control of $h r p L$ mRNA levels.

Previous reports have shown that PNPase plays an important role in sRNA turnover (Viegas et al. 2007; Andrade and Arraiano 2008). RsmB is an abundant regulatory sRNA in $D$. dadantii that has an essential role in the post-transcriptional regulation of $h r p L$ by antagonizing RsmA and alleviating the degradation effect of RsmA on $h r p L$ mRNA. We hypothesize that PNPase may regulate $h r p L$ through RsmA-RsmB. Northern blot analysis was performed to compare the RsmB RNA levels in D. dadantii 3937 and Ech152. A major RsmB transcript of approximately 250 nucleotides (nt) was observed in both the wild type and the pnp mutant (Fig. 4A). Interestingly, in Ech152, in addition to the 250-nt transcript, shorter RsmB transcripts of approximately 155,170 , and $210 \mathrm{nt}$ were observed in abundance (Fig. 4A). The RsmB transcript pattern was restored to that of the wild type when Ech152 was complemented with pML1231. Similar levels of $r s m A$ mRNA were observed in D. dadantii 3937 and Ech152, suggesting that PNPase does not have a regulatory effect on $r s m A$ (Fig. 4B). The total amount of RsmB transcripts (comprising full-length transcripts plus truncated transcripts) in Ech152 is much higher than the total amount of RsmB RNA transcripts (comprising full-length transcripts only) in D. dadantii 3937.

\section{RsmB truncated transcripts in pnp mutant have intact $5^{\prime}$ ends and incomplete $3^{\prime}$ ends.}

After deletion of pnp, an abundance of truncated RsmB transcripts were observed in Ech152. For this reason, we sought to 
determine which parts were missing from the truncated RsmB transcripts in Ech152. Therefore, a primer extension assay was performed to determine whether the truncated RsmB transcripts have the same 5' ends as the full-length RsmB transcripts in the wild type. Two primers were designed for use in the primer ex- tension analysis: primer 1 and primer 2 that anneal to the $5^{\prime}$ and $3^{\prime}$ ends of RsmB, respectively (Fig. 5B). Initial reactions with primer 1 yielded a single primer extension product (band I) in both the wild type and Ech152, which indicates that the $5^{\prime}$ ends of the RsmB transcripts in both strains are intact and identical

Table 1. Strains, plasmids, and primers used in this study

\begin{tabular}{|c|c|c|}
\hline $\begin{array}{l}\text { Strains, plasmids, and } \\
\text { primers }^{\mathrm{a}}\end{array}$ & Characteristics or sequences $\left(5^{\prime} \text { to } 3^{\prime}\right)^{b}$ & Reference or source \\
\hline \multicolumn{3}{|l|}{$\begin{array}{l}\text { Strains } \\
\end{array}$} \\
\hline Dickeya dadantii 3937 & Wild-type strain of $D$. dadantii isolated from Saintpaulia ionantha & $\begin{array}{l}\text { Hugouvieux-Cotte-Pattat, N., } \\
\text { UMR-CNRS, Villeneuve, France }\end{array}$ \\
\hline Ech152 & D. dadantii 3937 spnp::kan, $\mathrm{Km}^{\mathrm{r}}$ & This work \\
\hline Ech153 & D. dadantii 3937 with transposon miniHimar RBI insertion in $r s m B, \mathrm{Km}^{\mathrm{r}}$ & Yang et al. 2008a \\
\hline \multicolumn{3}{|c|}{ 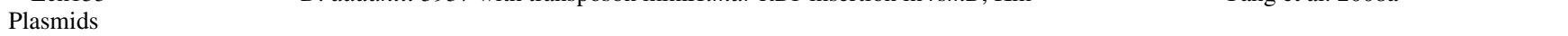 } \\
\hline pWM91 & Sucrose-based counter-selectable plasmid, $\mathrm{Ap}^{\mathrm{r}}$ & Metcalf et al. 1996 \\
\hline pML1233 & pML123 derivative with PCR fragment containing full length $r s m B, \mathrm{Gm}^{\mathrm{r}}$ & This work \\
\hline pML1234 & $\begin{array}{l}\text { pML123 derivative with PCR fragment containing } r \operatorname{sm} B \text { with an intact } 5^{\prime} \text { end and an } \\
\text { incomplete } 3^{\prime} \text { end lacking } 41 \mathrm{bp}, \mathrm{Gm}^{\mathrm{r}}\end{array}$ & This work \\
\hline pML1235 & $\begin{array}{l}\text { pML123 derivative with PCR fragment containing } r s m B \text { fragment with an intact } 5^{\prime} \text { end } \\
\text { and an incomplete } 3^{\prime} \text { end lacking } 88 \mathrm{bp}, \mathrm{Gm}^{\mathrm{r}}\end{array}$ & This work \\
\hline pPROBE-AT & Promoter-probe vector, $\mathrm{Ap}^{\mathrm{r}}$ & Miller et al. 2000 \\
\hline phrpA & pPROBE-AT derivative with PCR fragment containing hrpA promoter region, $\mathrm{Ap}^{\mathrm{r}}$ & Yang et al. 2008B \\
\hline \multicolumn{3}{|l|}{ Primers } \\
\hline PNP A & TCGGCGCCTGTTCTATCTAT & This work \\
\hline PNP_B & GGGACTCTGGGGTTCGAAATCTAGAATCCATGCTGACCATTAC & This work \\
\hline PNP C & CCAGTAGCTGACATTCATCCCTCGAGATTTCAAAGTGGCCGGTA & This work \\
\hline PNP_D & CATCGTAAGGAGCTGCCAATC & This work \\
\hline PNP F & GACCTAGGCGAGAAGCTG & This work \\
\hline PNP_R & CTATTGCTGGTCCGATCC & This work \\
\hline rsmB_F & GTCGCCACGCAGGATAGC & This work \\
\hline $\mathrm{rsmB} \mathrm{R}$ & CATGGTATCGATGCAGAACG & This work \\
\hline rsmB1234_F & CAAGAGCTCACCTTGTTGCTTCCCTGCTC & This work \\
\hline $\mathrm{rsmB} 1234 \mathrm{R}$ & GCATCTAGAGTCGCCACGCAGGATAGC & This work \\
\hline rsmB1235_F & CAAGAGCTCGTCCCTGATGGTCCTCCTA & This work \\
\hline rsmB1235_R & GCATCTAGAGTCGCCACGCAGGATAGC & This work \\
\hline$h r p N$ reverse-gRTPCR & CCAGCGACAACGGCGAGAA & This work \\
\hline$d s p E$ forward-qRTPCR & GATGGCGGAGCTGAAATCGTTC & This work \\
\hline$d s p E$ reverse-qRTPCR & CCTTGCCGGACCGCTTATCATT & This work \\
\hline$r p o N$ forward-qRTPCR & ACTGGCGCTGGAAAGCAACC & This work \\
\hline$r p o N$ reverse-qRTPCR & GGCAGCTCGTCGGGCATATC & This work \\
\hline hrpL forward-qRTPCR & GATGATGCTGCTGGATGCCGATGT & This work \\
\hline hrpL reverse-qRTPCR & TGCATCAACAGCCTGGCGGAGATA & This work \\
\hline$h r p S$ forward-gRTPCR & TGGAAGGCGAAACCGGCACC & This work \\
\hline hrpS reverse-qRTPCR & GCACGGCGGCGCAGTTCAC & This work \\
\hline hrpA forward-Northern & GGGACTTTCTAACGCAGCAG & This work \\
\hline hrpA reverse-Northern & AATAGCTTTGGCCGCTTTCT & This work \\
\hline$r s m A$ forward-Northern & CGAGTTGGCGAAACCCTCAT & This work \\
\hline$r s m A$ reverse-Northern & AATAGGAGGTAGGCTGAGAC & This work \\
\hline$r \operatorname{sm} B$ forward-Northern & CGCGATTTTTGTACGGCTAT & This work \\
\hline$r s m B$ reverse-Northern & CGATTTCTCGGTTCCCTCTT & This work \\
\hline RsmB primer 1 & TTTAGGCTCCTGCCCCACC & This work \\
\hline RsmB primer 2 & CTCTTAGTTCGTTTGCAGCAGTCC & This work \\
\hline \multirow{2}{*}{ RsmB probe I } & ССССАCСGGCATTCCCAGGCCGGCTCTCАTTCTCCATCCTGGAGGTGTCССТАA & \\
\hline & TTTCATCCTGAAA & This work \\
\hline \multirow[t]{2}{*}{ RsmB probe II } & AGGGAACCGATTTCTCGGTTCCCTCTTAGTTCGTTTGCAGCAGTCCCGCTACCT & \\
\hline & TGTTGCTTCCCTGCTCGTCCTT & This work \\
\hline
\end{tabular}

\footnotetext{
${ }^{\mathrm{a}} \mathrm{qRTPCR}=$ quantitative reverse-transcription polymerase chain reaction.
}

${ }^{\mathrm{b}} \mathrm{Km}^{\mathrm{r}} \mathrm{Ap}^{\mathrm{r}}$ and $\mathrm{Gm}^{\mathrm{r}}$ indicate kanamycin, gentamycin, and ampicillin resistance, respectively. $\mathrm{PCR}=$ polymerase chain reaction. 
(Fig. 5A and B). In addition, the primer extension signal produced by primer 1 was considerably stronger in Ech 152 compared with the wild type (signal intensity ratio of Ech152/D. dadantii $3937=4.38$ using primer 1) (Fig. 5A). Based on the signal intensity, this result also suggests that the abundant truncated RsmB transcripts observed in Ech152 have intact 5' ends that could be detected in abundance by primer 1 in the primer extension assay.

Subsequent primer extension analysis using primer 2 (anneals to $3^{\prime}$ end of RsmB) was also performed to compare the 5' ends of RsmB transcripts in the wild type and Ech152. Reactions with primer 2 also yielded a single primer extension product (band II), indicating that the $5^{\prime}$ ends of $\mathrm{RsmB}$ are identical in Ech152 and wild-type strains. Interestingly, the Ech152 primer extension signal produced by primer 2 was only slightly more intense than the signal in the wild-type strain (signal intensity ratio of Ech152/D. dadantii $3937=1.57$ using primer 2) (Fig. 5A). Because primer 2 anneals to the $3^{\prime}$ end of RsmB, only those transcripts with intact $3^{\prime}$ ends will produce a primer extension signal (Fig. 5B, scheme of primer extension analysis

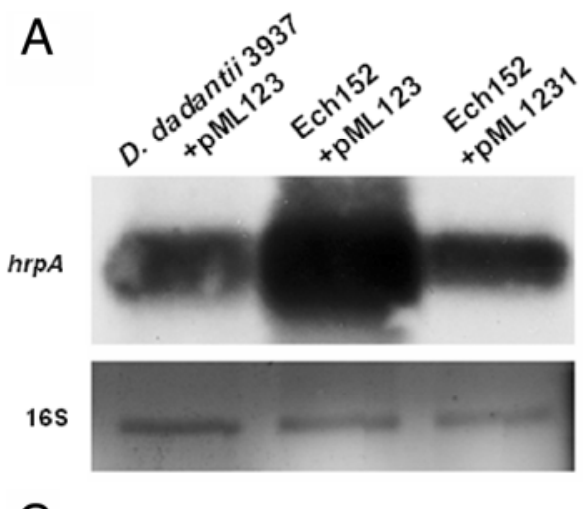

B
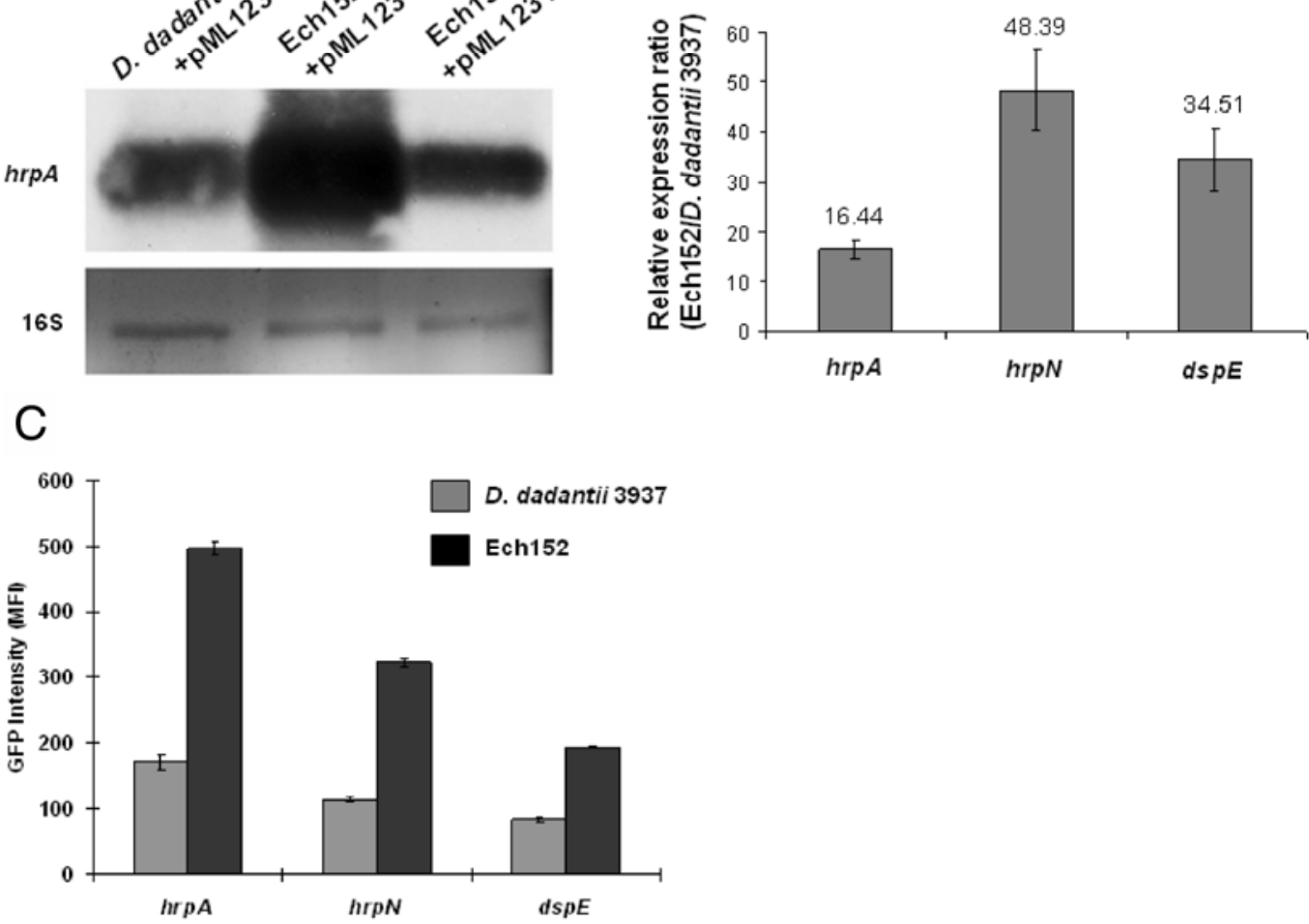

Fig. 1. A, Northern blot analysis of Dickeya dadantii 3937 with plasmid pML123, pnp mutant Ech152 with pML123, and pML1231 using hrpA as a hybridization probe. 16S rRNA was used as RNA loading control. B, Relative mRNA levels of $h r p A$, hrpN, and $d s p E$ in Ech152 compared with D. dadantii 3937, measured by real-time polymerase chain reaction. Similar results have been observed in two independent experiments. C, Promoter activities of $h r p A$, $h r p N$, and $d s p E$ in D. dadantii 3937 (gray bar) and Ech152 (black bar). D. dadantii 3937 and Ech152 carrying reporter plasmids phrpA, phrpN, and pdspE were cultured in minimal medium at $28^{\circ} \mathrm{C}$ for $12 \mathrm{~h}$ and the promoter activities were measured by flow cytometry. Values of mean fluorescence intensity are average green fluorescent protein fluorescence intensities of total bacterial population and are representative of two experiments. Three replicates were used in this experiment.
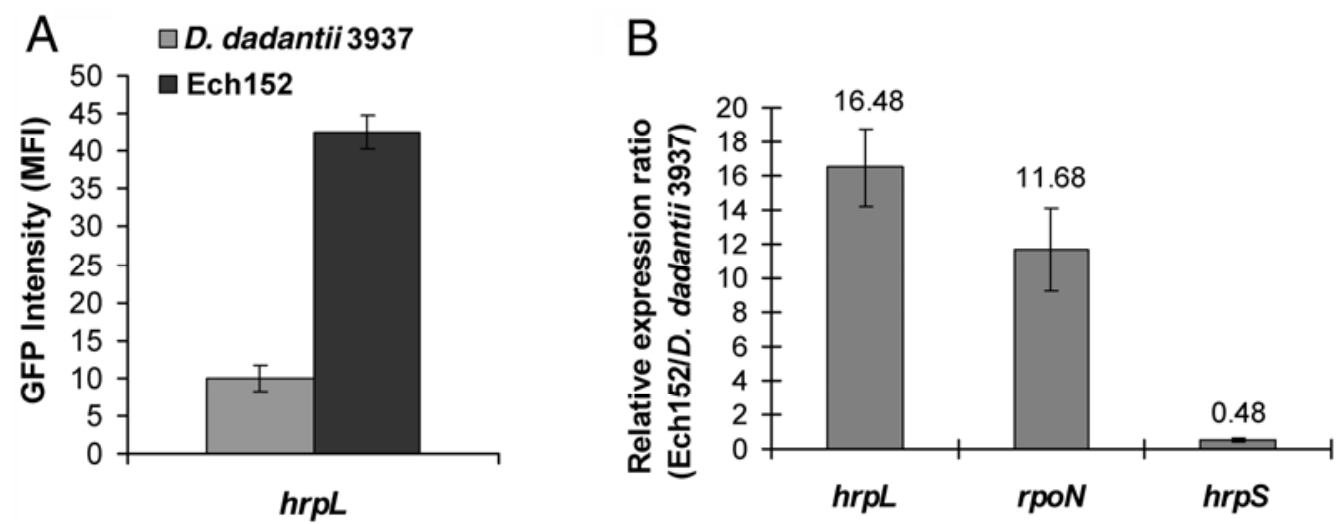

Fig. 2. A, Promoter activities of hrpL in Dickeya dadantii 3937 (gray bar) and in Ech152 (black bar). B, Relative mRNA levels of $h r p L$, rpoN, and $h r p S$ of Ech152 compared with $D$. dadantii 3937, measured by real-time polymerase chain reaction. D. dadantii 3937 and Ech 152 carrying reporter plasmids phrpA, phrpN, and pdspE were cultured in minimal medium at $28^{\circ} \mathrm{C}$ for $12 \mathrm{~h}$ and the promoter activities were measured by flow cytometry. Values of mean fluorescence intensity are average green fluorescent protein fluorescence intensities of total bacterial population and are representative of two experiments. Three replicates were used in this experiment. 
with primer 1 and primer 2). Primer extension signals of similar intensity were produced in both Ech152 and the wild type, which suggests that the population of truncated RsmB transcripts that are most abundant in Ech152 lack different portions from the $3^{\prime}$ ends and are unable to generate a signal with primer 2 (Fig. 5B).

Finally, a Northern blot was performed to compare the $3^{\prime}$ and $5^{\prime}$ ends of RsmB transcripts in Ech152 with those of the wild-type strain. In this assay, two hybridization probes were used, probe I (anneals to the 5' end of RsmB) and probe II (anneals to the $3^{\prime}$ end of RsmB). Similar to the product generated by the full-length RsmB probe (Fig. 4A), an RsmB transcript pattern consisting of full-length and multiple truncated RsmB transcripts was observed in Ech152 using probe I (Fig. 5C). However, when probe II was used in the Northern blot, only two major bands were detected in Ech152 (Fig. 5C). Again, these results confirm that the truncated RsmB transcripts present in Ech152 have similar intact 5' ends detectable by probe I but incomplete $3^{\prime}$ ends that are undetectable by probe II (Fig. 5D).

\section{Sequestering activity}

of artificially designed truncated RsmB transcripts.

In addition to the full-length 250-nt transcript, abundant 3'end truncated RsmB transcripts (sizes of 155, 170, and $210 \mathrm{nt}$ ) were present in Ech152 (Fig. 4A). Given that RsmB is an un-

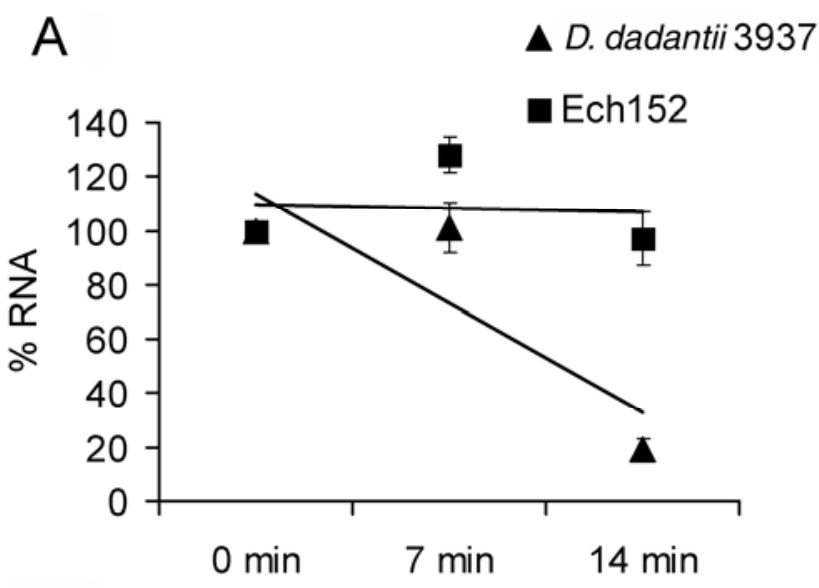

B

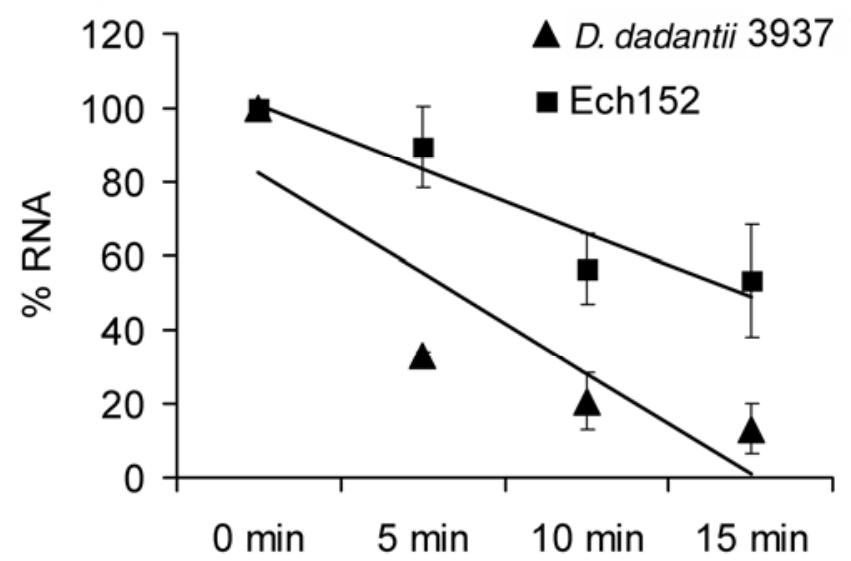

Fig. 3. A, rpoN RNA stability in Dickeya dadantii 3937 (triangles) and in Ech152 (squares). Slopes of rpoN RNA decay curves of D. dadantii 3937 and Ech152 are -40.5 and -1.45 , respectively. $\mathbf{B}, \operatorname{hrpL}$ RNA stability in $D$. dadantii 3937 (triangles) and in Ech152 (squares). Slopes of hrpL RNA decay curves of D. dadantii 3937 and Ech152 are -28.28 and -17.29 , respectively. Similar results were observed in two independent experiments and the result of one is shown here. translated sRNA which functions by directly binding RsmA to sequester its degradation effect on T3SS, we speculate that these truncated RsmB transcripts are still able to bind and sequester RsmA. Two artificially designed $r s m B$ DNA fragments encoding transcripts with intact $5^{\prime}$ ends and truncated $3^{\prime}$ ends were cloned into pML123, generating the complementation plasmids pML1234 and pML1235. pML1234 contains an rsmB fragment that includes the $r s m B$ promoter region, an intact $5^{\prime}$ end of the $\operatorname{rsm} B$ gene, and a truncated $3^{\prime}$ end lacking the last $41 \mathrm{bp}$ of $r s m B$. pML1235 contains an $r \operatorname{smB}$ fragment that includes the $r s m B$ promoter region, an intact $5^{\prime}$ end of the $r s m B$ gene, and a truncated $3^{\prime}$ end lacking the last $88 \mathrm{bp}$ of $r \mathrm{smB}$. Another plasmid containing full-length $\operatorname{rsmB}$ was also constructed and designated pML1233 (Table 1). The plasmids pML1233, pML1234, and pML1235 were each electroporated into an $r \operatorname{smB}$ mutant (Ech153), and the hrpA expression in the wild type and Ech153 carrying the different complementation plasmids was examined by Northern blot. In $D$. dadantii, the expression of $h r p A$ is regulated by the RsmA-RsmB pair through HrpL (Yang et al. 2008a). Thus, the level of hrpA expression reflects the ability of RsmB sRNA to sequester the degradation effect of RsmA on $h r p L$ mRNA. The Northern blot analysis showed that the $h r p A$ expression was completely abolished in Ech153 (Fig. 6). However, the level of $h r p A$ mRNA in Ech153 was restored by pML1233. Interestingly, the plasmids pML1234 and pML1235 carrying artificially designed $3^{\prime}$ end truncated $r s m B$ fragments could partially restore hrpA expression in Ech153 (Fig. 6). The sequestration effect of these 3'-end truncated RsmB fragments on RsmA was also confirmed by measuring the promoter activity of $h r p A$ in the wild type and Ech153 carrying pML1233, pML1234, or pML1235. The complementation plasmid pML1233 was able to restore $h r p A$ promoter activity in Ech153 (Table 2). The hrpA promoter activity was partially restored upon introduction of pML1234 and pML1235 into Ech153 (Table 2). These results suggest that RsmB transcripts with short truncations at the $3^{\prime}$ end may retain the ability to sequester RsmA, and as a consequence, enhance $h r p A$ expression, albeit with reduced activity.

\section{Bistable expression of T3SS genes.}

A subpopulation of $D$. dadantii 3937 cells grown in a homogenous medium was shown to have elevated expression of $d s p E$ (Peng et al. 2006). The expression level of $d s p E$ in the total cell population can be divided into low-state (basal level

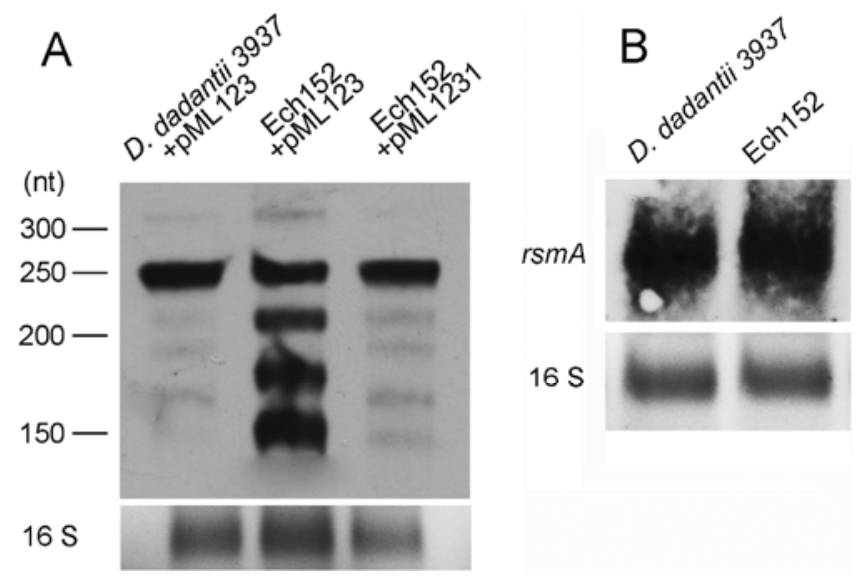

Fig. 4. A, Northern blot analysis of Dickeya dadantii 3937 with plasmid pML123, pnp mutant Ech152 with pML123, and Ech152 with plasmid pML1231 using a full-length $\operatorname{rsmB}$ hybridization probe. A biotin-labeled RNA marker was used to determine the size of the RsmB RNA fragments. B, Northern blot analysis of D. dadantii 3937 and Ech152 using an rsmA probe. 
of T3SS gene expression) and high-state (high level of T3SS gene expression). In this study, single-cell gene expression patterns of $h r p A, h r p N, d s p E, h r p L, h r p S$, and $r s m A$ were further examined in $D$. dadantii 3937 carrying the promoter- $g f p$ transcriptional fusion constructs phrpA, phrpN, pdspE, phrpL, phrpS, and prsmA, respectively, by FACS. Interestingly, only the T3SS structural and effector genes $h r p A, h r p N$, and $d s p E$ showed a bistable gene expression pattern (Fig. 7A, gray shade). The T3SS regulatory genes $h r p S$, $h r p L$, and $r s m A$ showed a monostable gene expression pattern (Supplementary Fig. 1).

Because an increase in expression of the T3SS structural and effector genes was observed in Ech152, we examined the role of PNPase in regulating the bistable gene expression of $h r p A, h r p N$, and $d s p E$. Gene expression patterns of the T3SS genes were analyzed in Ech152 by FACS (Fig. 7A, black line). Compared with the wild-type strain, an increased and monophasic-like expression of $h r p A, h r p N$, and $d s p E$ was observed in Ech152 cells after $12 \mathrm{~h}$ (Fig. 7A, black line). Although a majority of Ech152 cells expressed $h r p A$ at the high-state level at $12 \mathrm{~h}$ (Fig. 7A, black line), a subpopulation of cells expressed hrpA at the low-state level in Ech152 in the early growth stages (Fig. 7B, 7, 9, and 11 h, black line). Similarly, a bistable gene expression pattern of $h r p N$ and $d s p E$ was observed in the pnp mutant in the early growth stages but a monomodal-like

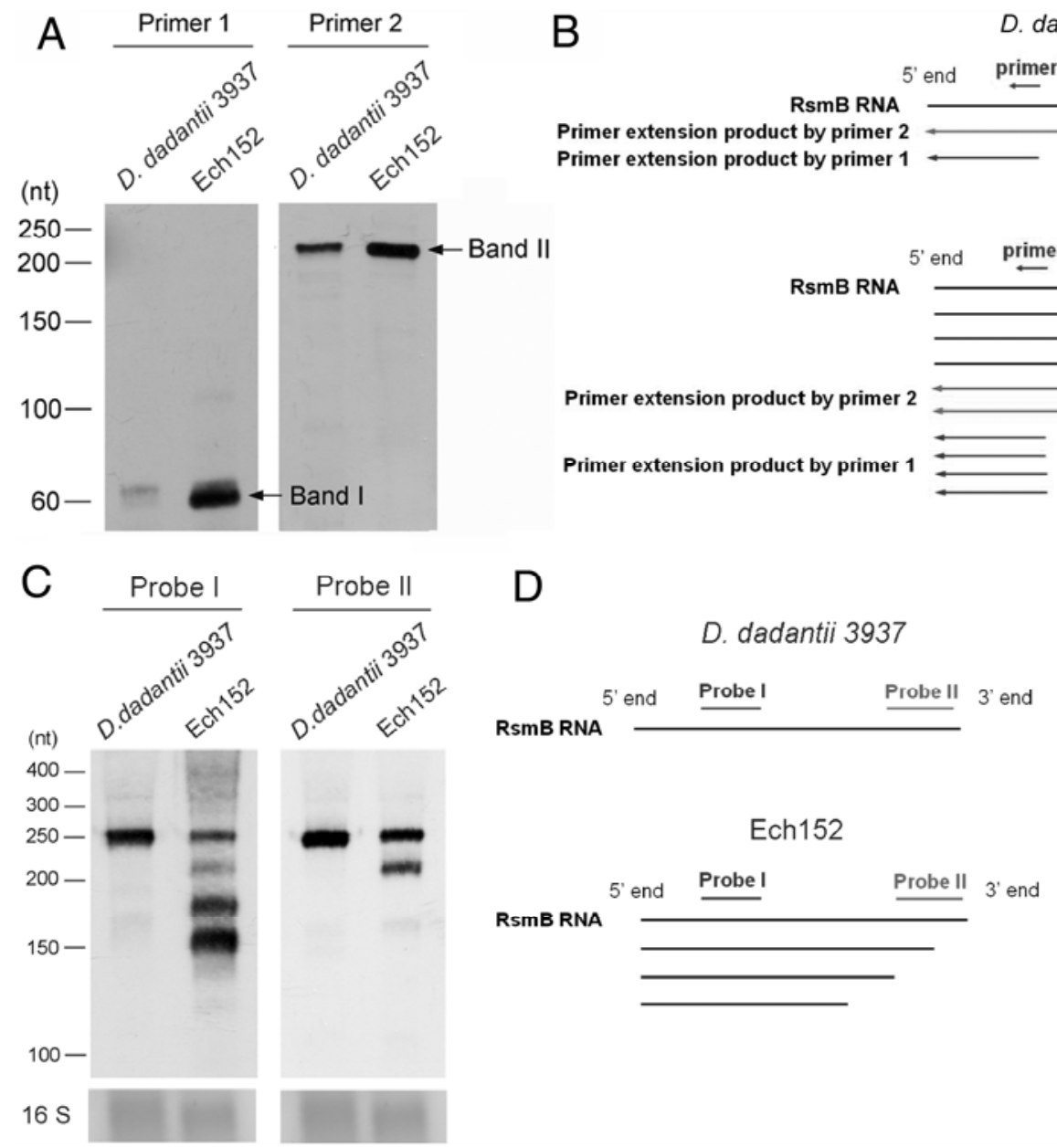

Fig. 5. A, Primer extension assay of RsmB in Dickeya dadantii 3937 and Ech152 using primer 1 (anneals to the $5^{\prime}$ end of RsmB RNA) and primer 2 (anneals to the $3^{\prime}$ end of RsmB RNA). Bacterial strains were grown in minimal medium at $28^{\circ} \mathrm{C}$ for $12 \mathrm{~h}$. Similar results were observed among three individual experiments. B, Scheme of primer extension analysis with primer 1 and primer 2. C, Northern blot analysis of Dickeya dadantii 3937 and Ech152 using $r s m B$ probe I and probe II. D, Scheme of Northern blot analysis with probe I and probe II.

Table 2. hrpA promoter activity in Dickeya dadantii 3937 carrying plasmid pML123 and rsmB mutant Ech153 carrying plasmids pML123, pML1233, pML1234, and pML1235

\begin{tabular}{|c|c|c|c|}
\hline \multirow[b]{2}{*}{ Gene Promoter } & \multicolumn{3}{|c|}{ Mean fluorescence intensity ${ }^{b}$} \\
\hline & $6 \mathrm{~h}$ & $12 \mathrm{~h}$ & $24 \mathrm{~h}$ \\
\hline D. dadantii 3937 (phrpA, pML123) & $46.0 \pm 5.6$ & $110.4 \pm 3.7$ & $140.3 \pm 8.4$ \\
\hline Ech153 (phrpA, pML123) & $4.2 \pm 2.8$ & $4.4 \pm 0.8$ & $7.8 \pm 2.1$ \\
\hline Ech153 (phrpA, pML1233) & $90.1 \pm 4.4$ & $210.1 \pm 12.9$ & $252.7 \pm 13.6$ \\
\hline Ech153 (phrpA, pML1234) & $23.2 \pm 3.4$ & $61.7 \pm 6.9$ & $42.2 \pm 5.5$ \\
\hline Ech153 (phrpA, pML1235) & $19.1 \pm 1.9$ & $44.1 \pm 3.2$ & $36.2 \pm 5.3$ \\
\hline D. dadantii 3937 (pPROBE-AT) & $2.3 \pm 0.1$ & $9.8 \pm 1.4$ & $8.2 \pm 3.7$ \\
\hline
\end{tabular}

${ }^{a}$ D. dadantii 3937 carrying pPROBE-AT was used as a control for basal level of green fluorescent protein (GFP) expression.

${ }^{\mathrm{b}}$ Promoter activities were measured at 6,12 , and $24 \mathrm{~h}$ of bacterial growth in minimal medium at $28^{\circ} \mathrm{C}$ by flow cytometry. Values of mean fluorescence intensity are average GFP fluorescence intensities of total bacterial population and are representative of two experiments. Three replicates were used in this experiment. 
expression pattern was observed after $12 \mathrm{~h}$ (data not shown). Because PNPase regulates the transcription of $h r p L$ but does not have a regulatory effect on HrpS and RsmA (Figs. 2B and 4B), an increase in $h r p L$ promoter activity but similar gene expression patterns of hrpS and rsmA were observed in Ech152 compared with $D$. dadantii 3937.

\section{DISCUSSION}

PNPase is a well-known exoribonuclease that is ubiquitous in bacteria and eukaryotes. In this work, we presented evidence that PNPase plays an important role in the regulation of T3SS in D. dadantii (Fig. 8). We revealed that, by reducing the rpoN mRNA stability, PNPase downregulates the transcription of hrpL and, consequently, the transcription of T3SS structural and effector genes. To our knowledge, this is the first report describing the regulation of PNPase on the T3SS of a phytopathogenic bacterium. In addition, we also provided evidence that PNPase affects the RsmB turnover by controlling the levels of fragmented RsmB transcripts in D. dadantii. Although we do not have direct evidence that these fragmented RsmB transcripts are functional in vivo or that their presence in the cell contributes to the control of T3SS expression, the information we present here provides innovative insights toward understanding the relationship between the structural integrity of the regulatory sRNAs and their function during the regulation of T3SS.

In Yersinia spp., PNPase plays an important role in controlling the expression of T3SS genes. PNPase deficiency results in increased expression of T3SS genes under in vitro growth conditions (Rosenzweig et al. 2007). However, because the transcription of those T3SS genes showed no difference among the wild type and pnp mutant, the author proposed that PNPase might regulate the T3SS genes at the post-transcriptional level. In contrast, our results showed that PNPase regulates the transcription of the T3SS structural and effector genes through the T3SS master regulator HrpL in $D$. dadantii. In addition, similar hrpA RNA degradation rates have been observed in $D$. dadantii and Ech152 (Supplementary Fig. 2). This result further demonstrates that, apart from Yersinia spp., PNPase does not directly regulate the T3SS structural and effector genes in $D$. dadantii. In $S$. enterica, PNPase downregulates the expression of Salmonella plasmid virulence genes ( $s p v$ genes) through SpvR (Ygberg et al. 2006). PNPase controls the T3SS through a master regulator in both Dickeya and Salmonella spp. How-

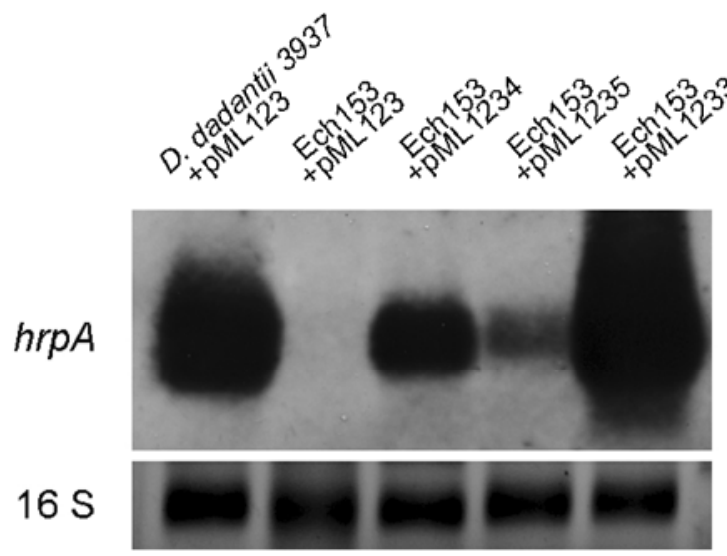

Fig. 6. Northern blot analysis of Dickeya dadantii 3937 with plasmid pML123 and the rsmB mutant (Ech153) with plasmids pML123, pML1234, pML1235, and pML1233, using hrpA as a hybridization probe. pML1233 contains the full-length $r s m B$ fragment. pML1234 contains an $r s m B$ fragment lacking $41 \mathrm{bp}$ from the $3^{\prime}$ end and pML1235 contains an $r s m B$ fragment lacking $88 \mathrm{bp}$ from the $3^{\prime}$ end. pML123 is the empty vector control. ever, unlike HrpL, which activates the expression of T3SS genes as an ECF family alternative $\sigma$ factor, SpvR regulates $s p v$ genes as a transcriptional regulator and its activation requires the participation of $\sigma$ factor RpoS. It is interesting to realize that, although Yersinia, Salmonella, and Dickeya spp. infect different hosts, regulation of their T3SS genes all involve PNPase. This gives us some indication that PNPase might serve as a general
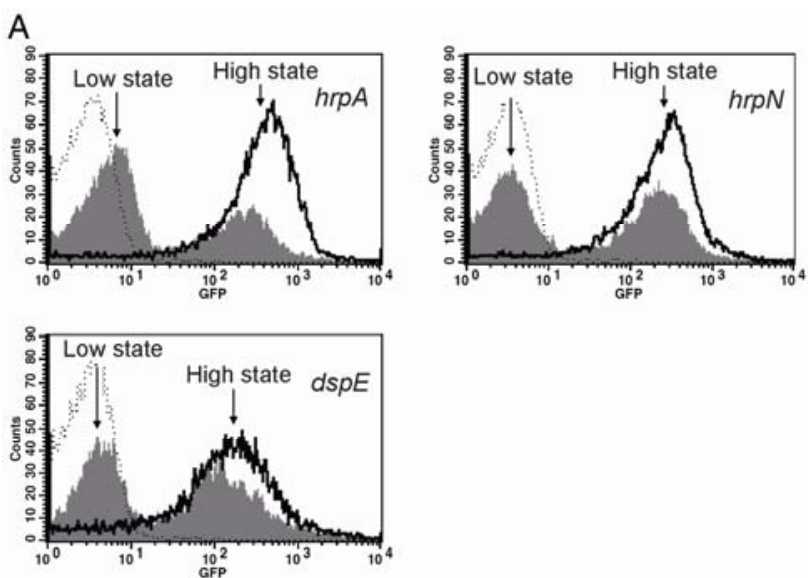

B
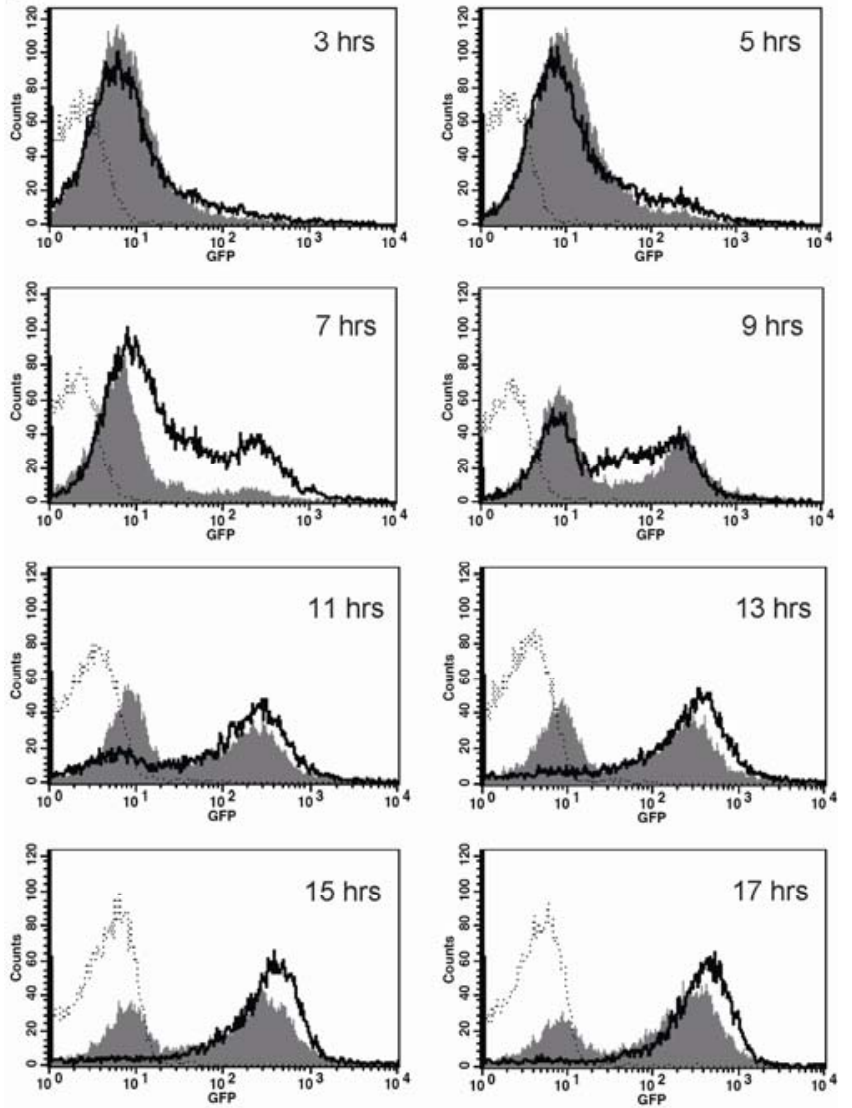

Fig. 7. A, Expression patterns of $h r p A, h r p N$, and $d s p E$ in Dickeya dadantii 3937 and Ech152. D. dadantii 3937 and Ech152 carrying reporter plasmids phrpA, phrpN, and pdspE were cultured in minimal medium at $28^{\circ} \mathrm{C}$ for $12 \mathrm{~h}$ and the promoter activities were measured by flow cytometry. B, Expression pattern of hrpA in Dickeya dadantii 3937 and Ech152 at different time points of growth in minimal medium at $28^{\circ} \mathrm{C}$. In both $\mathrm{A}$ and $\mathrm{B}$, the $y$-axis represents the cell counts and the $\mathrm{x}$-axis represents green fluorescent protein (GFP) intensity (mean fluorescence intensity). The dotted line depicts the basal level of GFP expression in D. dadantii 3937 containing pPROBE-AT vector control. The gray shade represents expression patterns of target genes in $D$. dadantii 3937 and the black line represents expression patterns of target genes in Ech152. 
mechanism to fine tune the control of virulence gene expression in different bacterial pathogens.

In this study, it appears that PNPase plays an important role in RsmB turnover in D. dadantii 3937, and the absence of PNPase activity results in the production of abundant truncated RsmB transcripts in Ech152. At this stage, it is uncertain whether these truncated RsmB transcripts are still biologically functional and maintain the ability to sequester RsmA. Artificially designed truncated RsmB transcripts lacking either 41 or $88 \mathrm{nt}$ from the $3^{\prime}$ end could partially restore the complete lack of $h r p A$ expression in the $r s m B$ mutant (Fig. 6; Table 2). This suggests that the $3^{\prime}$ truncated $\mathrm{RsmB}$ transcripts in the pnp mutant may remain biologically functional and retain partial RsmA sequestering activity, which would result in a reduction of $h r p L$ mRNA degradation in Ech152. Indeed, 14 putative RsmA-binding sites were predicted in the full-length 250-nt RsmB RNA of D. dadantii 3937 (Supplementary Fig. 3). These RsmA-binding sites are primarily located within the loops of predicted stem-loops of the RsmB RNA secondary structure. The truncated RsmB transcripts in Ech152 still contain many of the predicted RsmA binding sites at the $5^{\prime}$ end, which suggests that these truncated transcripts may still be able to bind to RsmA.

In Escherichia coli, both CsrB (RsmB homologue) and CsrC sRNAs contain multiple binding sites to bind CsrA (RsmA homologue) and sequester its regulatory function (Liu et al. 1997). Dubey and associates (2005) demonstrated that randomly synthesized RNA ligands containing single CsrAbinding sites with an appropriate stem loop structure can bind to the CsrA protein in vitro. In comparison, our results showed that, although the fragmented RsmB RNAs retain the majority of the RsmA-binding sites after truncation at the $3^{\prime}$ end, their RsmA sequestering ability has been significantly compromised (Fig. 6). This implies that a single RsmA-binding site with an appropriate secondary structure may be sufficient to bind RsmA but structural integrity is crucial for proper regulatory function of RsmB.

In Bacillus subtilis, comK, a gene encoding a master transcriptional activator, displays a bistable gene expression pattern during the late exponential growth phase. This leads to the bistable expression of the genes responsible for competence development and causes the separation of competent and noncompetent populations in the bacterial cells (Hahn et al. 1994). Bistable expression patterns of $h r p A, h r p N$, and $d s p E$ were observed in D. dadantii 3937 (Fig. 7A.). However, the T3SS master regulator gene $h r p L$ does not show a bistable expression pattern in $D$. dadantii 3937. This observation is different than that reported on the bistable expression of competence development genes in B. subtilis. Compared with the wild-type strain, a high level of $h r p L$ expression and a constant bistable expression pattern of $h r p A, h r p N$, and $d s p E$ with a large proportion of high state cells were observed in Ech152 (Fig. 7A). This result suggests that PNPase controls the ratio of cells that express high-state and low-state levels of $h r p A, h r p N$, and $d s p E$. By repressing $h r p L$ expression, PNPase prevents the shift of hrpA expression from the lowstate toward the high-state level. In addition, because bistable expression patterns of $h r p A, h r p N$, and $d s p E$ were observed in Ech152 at the early stage of bacterial growth, it is unlikely that PNPase is the key regulator involved in the switch from

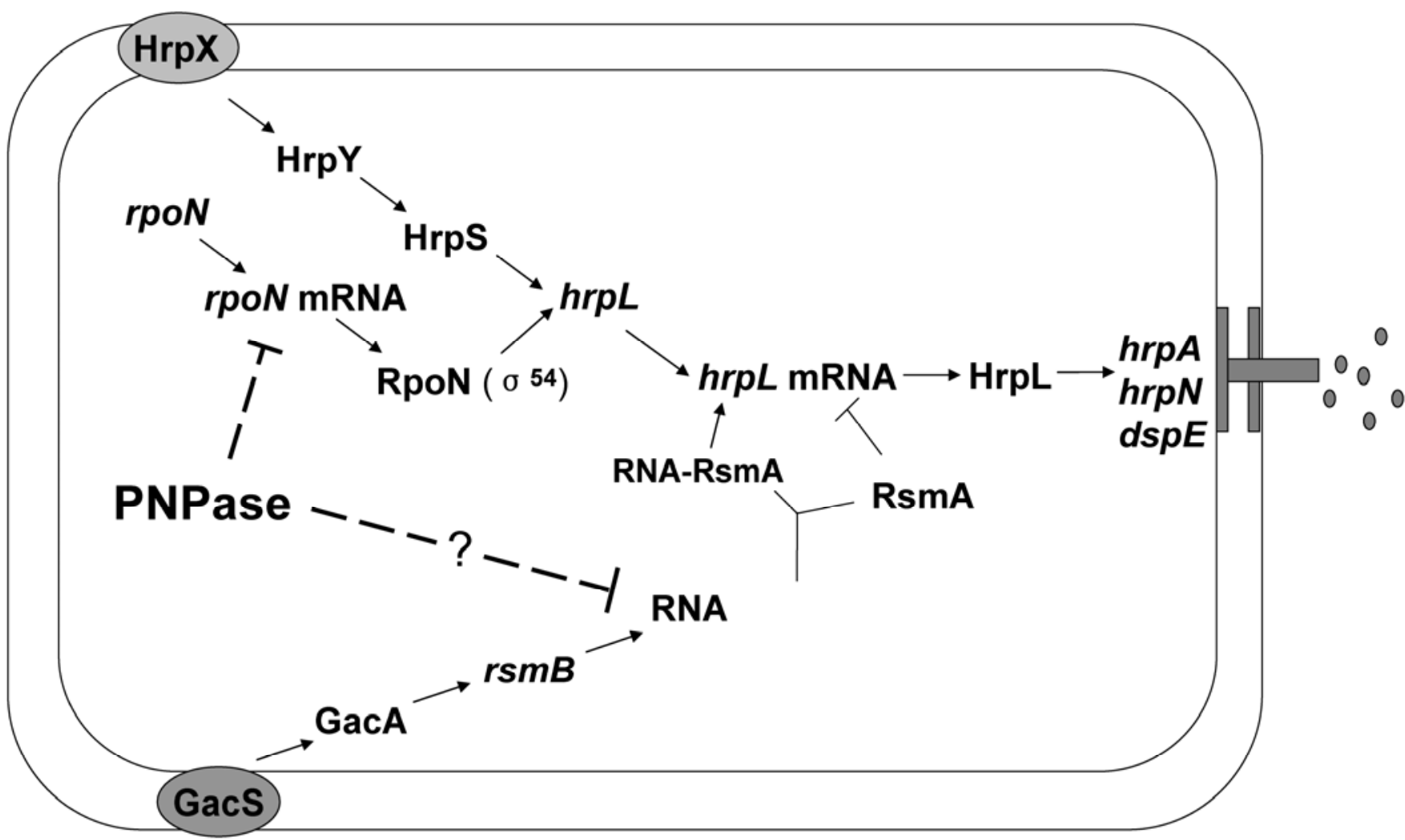

Fig. 8. Model of type III secretion system (T3SS) gene regulation by polynucleotide phosphorylase (PNPase) in Dickeya dadantii. HrpL, the master regulator of the T3SS structural and effector genes, activates the transcription of $h r p A, h r p N$, and $\operatorname{ssp} E$. The transcription of $h r p L$ is upregulated by HrpS, an enhancer protein, in conjunction with RpoN, a $\sigma^{54}$ factor. $h r p L$ mRNA stability is controlled by RsmA, a small-RNA-binding protein which binds to $h r p L$ mRNA and promotes $h r p L$ mRNA degradation. GacS-GacA activates RsmB, which encodes a regulatory small RNA that binds to and neutralizes the degradation effect of RsmA on $h r p L$ mRNA. PNPase has a negative regulatory effect on the expression of T3SS genes $h r p A$, $h r p N$, and $d s p E$. PNPase downregulates $h r p L$ transcription by reducing $r p o N$ mRNA stability. PNPase also reduces $h r p L$ mRNA stability. In this report, it is speculated that PNPase has a negative effect on RsmB RNA levels and structural integrity and, thereby, is involved in the post-transcriptional modulation of $h r p L$. 
monostable to bistable expression of T3SS genes. The key regulator for the bistable expression of T3SS in $D$. dadantii 3937 is yet to be identified.

\section{MATERIALS AND METHODS}

\section{Bacterial strains, plasmids, and media.}

Bacterial strains and plasmids used in this study are listed in Table 1 . Wild-type $D$. dadantii 3937 and mutants were stored at $-80^{\circ} \mathrm{C}$ in $15 \%$ glycerol. D. dadantii strains were grown in Luria-Bertani (LB) medium or minimal medium at $28^{\circ} \mathrm{C}$ with glucose as the carbon source (Yang et al. 2007). E. coli strains were grown in $\mathrm{LB}$ at $37^{\circ} \mathrm{C}$. Antibiotics were added to the media at the following concentrations: kanamycin, $50 \mu \mathrm{g} / \mathrm{ml}$; gentamycin, $25 \mu \mathrm{g} / \mathrm{ml}$; and ampicillin, $100 \mu \mathrm{g} / \mathrm{ml}$. The pnp deletion mutant (Ech152) was constructed by crossover PCR mutagenesis as previously described (Yang et al. 2002). Briefly, DNA fragments flanking $p n p$ were amplified by PCR using primer sets PNP_A/PNP_B and PNP_C/PNP_D (Table 1). Crossover PCR was performed using the flanking regions and a kanamycin cassette as templates and primers PNP_A and PNP_D. The pnp deletion fragment was cloned into the SpeI/ NotI sites of pWM91. The resulting plasmid was mobilized into $D$. dadantii 3937 by electroporation. To select strains with chromosomal deletions, transconjugants with kanamycin and ampicillin resistance were plated on mannitol glutamate containing 5\% sucrose and kanamycin. Colonies having sucrose and kanamycin resistance and ampicillin sensitivity were isolated. The mutation was confirmed by PCR using primers PNP_F/PNP_R and by sequencing. The $r s m B$ transposon mutant Ech153 was obtained from a previous transposon mutant library (Yang et al. 2008a).

The plasmids pML1231 and pML1233 carrying pnp and $r s m B$, respectively, were constructed as follows. DNA fragments containing pnp or $r s m B$ with promoters and terminator regions were amplified by PCR from $D$. dadantii 3937 genomic DNA with primer sets PNP_F/PNP_R and rsmB_F/rsmB_R, respectively. The pnp and $r s m B$ fragments were purified, digested with $X b a I$ and $S a c I$, and cloned into the broad-host-range expression vector, pML123, digested with the same enzymes (Labes et al. 1990).

pML123 derivatives pML1234 and pML1235, containing DNA fragments encoding truncated RsmB transcripts with intact $5^{\prime}$ ends and incomplete $3^{\prime}$ ends, were constructed using the following method. DNA fragments containing the $r \operatorname{sm} B$ promoter and coding sequence lacking either 41 bp (rsmB41) or 88 bp ( $r s m B 88$ ) from the $3^{\prime}$ end were PCR amplified from D. dadantii 3937 genomic DNA with primer sets rsmB1234_F/rsmB1234_R and rsmB1235_F/rsmB1235_R, respectively. Another DNA fragment containing the terminator region of the $r s m B$ gene ( $r s m B$ Term) was also PCR amplified with Term_F and Term_R primers. The $3^{\prime}$ ends of the $r s m B 41$ and $r s m B 88$ fragments and the $5^{\prime}$ end of the $r s m B$ Term fragment were digested with $X b a \mathrm{I}$. $r s m B 41$ and $r s m B 88$ fragments were individually ligated to $r s m B$ Term and then amplified by PCR with primers rsmB1234/5_F and Term_R. The recombinant fragments were digested with $\mathrm{SacI}$ and $\mathrm{BamHI}$ and cloned into pML123 digested with the same enzymes to generate pML1234 (contains an $r s m B$ fragment which lacks 41 bp from the $3^{\prime}$ end) and pML1235 (contains an $r \operatorname{sm} B$ fragment which lacks 88 bp from the $3^{\prime}$ end). All the constructs have been confirmed by DNA sequencing.

The rsmA promoter region was PCR amplified from $D$. dadantii 3937 genomic DNA, ligated into the pCR2.1-TOPO TA cloning vector, and then subcloned into the $\mathrm{XbaI} / \mathrm{SacI}$ sites of the promoter- $g f p$ vector pPROBE-AT (Leveau and Lindow 2001), generating prsmA.
FACS assay.

The bacterial cells carrying promoter- $g f p$ transcriptional fusion plasmids were subcultured in minimal medium at $28^{\circ} \mathrm{C}$ to induce T3SS gene expression. Cells were harvested at the time points indicated in the respective figures, washed, and diluted to approximately $10^{6} \mathrm{CFU} / \mathrm{ml}$ with $1 \times$ phosphate-buffered saline $\left(8.0 \mathrm{~g}\right.$ of NaCl, $0.2 \mathrm{~g}$ of $\mathrm{KCl}, 1.44 \mathrm{~g}$ of $\mathrm{Na}_{2} \mathrm{HPO}_{4}$, and 0.24 $\mathrm{g}$ of $\mathrm{KH}_{2} \mathrm{PO}_{4}$ per liter, $\mathrm{pH} 7.2$ to 7.4 ) before analysis. The GFP fluorescence signals were measured using a four-color $\mathrm{BD}$ FACSCalibur (BD Biosciences, San Jose, CA, U.S.A.) equipped with 488- and 633-nm lasers. Bacteria were electronically gated based on forward and side light-scatter properties. All GFP fluorescence measurements were taken using the 488-nm laser and FL1 channel on the gated population. The results were analyzed using Cell Quest software (BD Biosciences).

\section{RNA extraction and real-time PCR analysis.}

Bacterial strains were cultured in minimal medium at $28^{\circ} \mathrm{C}$ for $12 \mathrm{~h}$. Total RNA was isolated by using the TRI reagent method (Sigma-Aldrich, St. Louis) and treated with Turbo DNA-free DNase (Ambion, Austin, TX, U.S.A.). The iScript cDNA synthesis kit (Bio-Rad, Hercules, CA, U.S.A.) was used to synthesize cDNA from $0.5 \mu \mathrm{g}$ of DNase-treated total RNA. The Real Master Mix (Eppendorf, Westbury, NY, U.S.A.) was used for real-time PCR reactions to quantify the cDNA level of target genes. $r p l U$ mRNA stability appears to be unaffected by PNPase (Supplementary Fig. 4) and, therefore, was used as an endogenous control for data analysis (Mah et al. 2003; Kuchma et al. 2005). Data were collected by the Opticon 2 system (BioRad) and analyzed using the Relative Expression Software Tool as described by Pfaffl and associates (2002). Primers used for the real-time PCR are listed in Table 1.

\section{Northern blot analysis.}

Bacterial strains were grown in minimal medium, and RNA was isolated and treated with DNase as mentioned above for real-time PCR analysis. Each RNA sample $(10 \mu \mathrm{g})$ was analyzed by Northern blot analysis using a NorthernMax kit (Ambion) according to the manufacturer's instructions. Hybridization probes used to detect the mRNA of target genes were PCR amplified and labeled with biotin using a BrightStar PsoralenBiotin kit (Ambion). Signals were developed using the BrightStar BioDetect kit (Ambion). 16S rRNA was visualized under UV transilluminator (Syngene, Frederick, MD, U.S.A.) and used as an internal control for normalization of RNA. For the Northern blot analysis of RsmB RNA, a $6 \mathrm{M}$ urea/6\% polyacrylamide gel was used to separate the sRNA fragments.

\section{Primer extension analysis.}

Primers used for reverse transcription were synthesized and labeled with biotin at the 5' end by Fisher Scientific (Pittsburgh). The reaction mixtures for synthesis of cDNA contained a total of $2 \mathrm{pmol}$ of primer, $10 \mu \mathrm{g}$ of RNA, and $200 \mathrm{U}$ of Superscript III RT (Invitrogen, Carlsbad, CA, U.S.A.). The primer extension products were separated in $6 \mathrm{M}$ urea/6\% polyacrylamide gels and transferred to nylon membranes (Immobilon-Ny+ Transfer Membrane; Millipore, Bedford, MA, U.S.A.). Signals were developed using a BrightStar BioDetect kit (Ambion). A biotinlabeled RNA marker (BrightStar RNA Century Markers; Ambion) was used to determine the sizes of the primer-extension products. The band intensities were quantified using a Bio Imaging system (Syngene).

\section{RNA stability assay.}

Bacterial strains were cultured in minimal medium at $28^{\circ} \mathrm{C}$ for $12 \mathrm{~h}$. Rifampicin $(500 \mu \mathrm{g} / \mathrm{ml})$ and nalidixic acid $(20 \mu \mathrm{g} / \mathrm{ml})$ were added to bacterial cultures to stop nucleic acid synthesis. 
Incubation was continued and culture aliquots were withdrawn at the times indicated in the respective figures. Bacterial cells were collected by centrifugation and were resuspended in RNAlater Solution (Ambion) to stop RNA decay. Total RNA was isolated and real-time PCR was performed to quantify the RNA of target genes using the methods described above. 16S rRNA was used as the endogenous control for data analysis. The percentage of RNA remaining after termination of RNA synthesis was calculated by comparing the amounts of $h r p L$ and rpoN mRNA measured at different time points with the quantity of mRNA present at time $0 \mathrm{~min}$. The mRNA stability curves were plotted and the slopes of the stability curves were calculated.

\section{ACKNOWLEDGMENTS}

This work is dedicated to Noel T. Keen. We thank N. Perna of the University of Wisconsin for providing access to the annotated $D$. dadantii genome sequences, D. A. Steeber for a technique support on flow cytometry, and M. L. P. Collin and M. J. McBride for critical discussions and reading of the manuscript. This project is supported by grants from the National Science Foundation (award no. EF-0332163), and the Research Growth Initiative of the University of Wisconsin-Milwaukee.

\section{LITERATURE CITED}

Alfano, J. R., and Collmer, A. 1997. The type III (Hrp) secretion pathway of plant pathogenic bacteria: Trafficking harpins, Avr proteins, and death. J. Bacteriol. 179:5655-5662.

Alfano, J. R., and Collmer, A. 2004. Type III secretion system effector proteins: Double agents in bacterial disease and plant defense. Annu. Rev. Phytopathol. 42:385-414.

Amblar, M., Barbas, A., Gomez-Puertas, P., and Arraiano, C. M. 2007. The role of the S1 domain in exoribonucleolytic activity: Substrate specificity and multimerization. RNA 13:317-327.

Andrade, J. M., and Arraiano, C. M. 2008. PNPase is a key player in the regulation of small RNAs that control the expression of outer membrane proteins. RNA 14:543-551.

Chatterjee, A., Cui, Y., and Chatterjee, A. K. 2002. Regulation of Erwinia carotovora $h r p L_{E c c}\left(\operatorname{sigma}-L_{E c c}\right)$, which encodes an extracytoplasmic function subfamily of sigma factor required for expression of the HRP regulon. Mol. Plant-Microbe Interact. 15:971-980.

Clements, M. O., Eriksson, S., Thompson, A., Lucchini, S., Hinton, J. C., Normark, S., and Rhen, M. 2002. Polynucleotide phosphorylase is a global regulator of virulence and persistency in Salmonella enterica. Proc. Natl. Acad. Sci. U.S.A. 99:8784-8789.

Deutscher, M. P. 2006. Degradation of RNA in bacteria: Comparison of mRNA and stable RNA. Nucleic Acids Res. 34:659-666.

Donovan, W. P., and Kushner, S. R. 1986. Polynucleotide phosphorylase and ribonuclease II are required for cell viability and mRNA turnover in Escherichia coli K-12. Proc. Natl. Acad. Sci. U.S.A. 83:120-124.

Dubey, A. K., Baker, C. S., Romeo, T., and Babitzke, P. 2005. RNA sequence and secondary structure participate in high-affinity CsrA-RNA interaction. RNA 11:1579-1587.

Galan, J. E., and Collmer, A. 1999. Type III secretion machines: Bacterial devices for protein delivery into host cells. Science 284:1322-1328.

Hahn, J., Kong, L., and Dubnau, D. 1994. The regulation of competence transcription factor synthesis constitutes a critical control point in the regulation of competence in Bacillus subtilis. J. Bacteriol. 176:57535761.

He, S. Y. 1998. Type III protein secretion systems in plant and animal pathogenic bacteria. Annu. Rev. Phytopathol. 36:363-392.

Hueck, C. J. 1998. Type III protein secretion systems in bacterial pathogens of animals and plants. Microbiol. Mol. Biol. Rev. 62:379-433.

Kinscherf, T. G., and Apirion, D. 1975. Polynucleotide phosphorylase can participate in decay of mRNA in Escherichia coli in the absence of ribonuclease II. Mol. Gen. Genet. 139:357-362.

Kuchma, S. L., Connolly, J. P., and O'Toole, G. A. 2005. A three-component regulatory system regulates biofilm maturation and type III secretion in Pseudomonas aeruginosa. J. Bacteriol. 187:1441-1454.

Kudla, J., Hayes, R., and Gruissem, W. 1996. Polyadenylation accelerates degradation of chloroplast mRNA. EMBO (Eur. Mol. Biol. Organ.) J. 15:7137-7146.

Kushner, S. R. 2002. mRNA decay in Escherichia coli comes of age. J. Bacteriol. 184:4658-4665.

Labes, M., Puhler, A., and Simon, R. 1990. A new family of RSF1010- derived expression and lac-fusion broad-host-range vectors for gramnegative bacteria. Gene 89:37-46.

Leszczyniecka, M., Kang, D. C., Sarkar, D., Su, Z. Z., Holmes, M., Valerie, K., and Fisher, P. B. 2002. Identification and cloning of human polynucleotide phosphorylase, hPNPase old-35, in the context of terminal differentiation and cellular senescence. Proc. Natl. Acad. Sci. U.S.A. 99:16636-16641.

Leveau, J. H., and Lindow, S. E. 2001. Predictive and interpretive simulation of green fluorescent protein expression in reporter bacteria. J. Bacteriol. 183:6752-6762.

Li, Z., and Deutscher, M. P. 1994. The role of individual exoribonucleases in processing at the $3^{\prime}$ end of Escherichia coli tRNA precursors. J. Biol. Chem. 269:6064-6071.

Liu, M. Y., Gui, G., Wei, B., Preston, J. F., 3rd, Oakford, L., Yuksel, U., Giedroc, D. P., and Romeo, T. 1997. The RNA molecule CsrB binds to the global regulatory protein CsrA and antagonizes its activity in Escherichia coli. J. Biol. Chem. 272:17502-17510.

Liu, Y., Cui, Y., Mukherjee, A., and Chatterjee, A. K. 1998. Characterization of a novel RNA regulator of Erwinia carotovora ssp. carotovora that controls production of extracellular enzymes and secondary metabolites. Mol. Microbiol. 29:219-234.

Mackie, G. A. 1998. Ribonuclease E is a 5'-end-dependent endonuclease. Nature 395:720-723.

Mah, T. F., Pitts, B., Pellock, B., Walker, G. C., Stewart, P. S., and O'Toole, G. A. 2003. A genetic basis for Pseudomonas aeruginosa biofilm antibiotic resistance. Nature 426:306-310.

Miller, W. G., Leveau, J. H. J., and Lindow, S. E. 2000. Improved $g f p$ and inaZ broad-host-range promoter-probe vectors. Mol. Plant-Microbe Interact. 13:1243-1250.

Mohanty, B. K., and Kushner, S. R. 2000. Polynucleotide phosphorylase functions both as a $3^{\prime} \rightarrow 5^{\prime}$ exonuclease and a poly(A) polymerase in Escherichia coli. Proc. Natl. Acad. Sci. U.S.A. 97:11966-11971.

Oussenko, I. A., Abe, T., Ujiie, H., Muto, A., and Bechhofer, D. H. 2005. Participation of $3^{\prime}-$ to- $^{\prime}$ ' exoribonucleases in the turnover of Bacillus subtilis mRNA. J. Bacteriol. 187:2758-2767.

Peng, Q., Yang, S., Charkowski, A. O., Yap, M. N., Steeber, D. A., Keen, N. T., and Yang, C. H. 2006. Population behavior analysis of $d s p E$ and pelD regulation in Erwinia chrysanthemi 3937. Mol. Plant-Microbe Interact. 19:451-457.

Pfaffl, M. W., Horgan, G. W., and Dempfle, L. 2002. Relative expression software tool (REST) for group-wise comparison and statistical analysis of relative expression results in real-time PCR. Nucleic Acids Res. 30:e36. Published online.

Polissi, A., De Laurentis, W., Zangrossi, S., Briani, F., Longhi, V., Pesole, G., and Deho, G. 2003. Changes in Escherichia coli transcriptome during acclimatization at low temperature. Res. Microbiol. 154:573-580.

Rosenzweig, J. A., and Schesser, K. 2007. Polynucleotide phosphorylase and the T3SS. Adv. Exp. Med. Biol. 603:217-224

Rosenzweig, J. A., Weltman, G., Plano, G. V., and Schesser, K. 2005. Modulation of Yersinia type three secretion system by the S1 domain of polynucleotide phosphorylase. J. Biol. Chem. 280:156-163.

Rosenzweig, J. A., Chromy, B., Echeverry, A., Yang, J., Adkins, B., Plano, G. V., McCutchen-Maloney, S., and Schesser, K. 2007. Polynucleotide phosphorylase independently controls virulence factor expression levels and export in Yersinia spp. FEMS (Fed. Eur. Microbiol. Soc.) Microbiol. Lett. 270:255-264.

Stickney, L. M., Hankins, J. S., Miao, X., and Mackie, G. A. 2005. Function of the conserved S1 and $\mathrm{KH}$ domains in polynucleotide phosphorylase. J. Bacteriol. 187:7214-7221.

Tang, X., Xiao, Y., and Zhou, J. M. 2006. Regulation of the type III secretion system in phytopathogenic bacteria. Mol. Plant-Microbe Interact. 19:1159-1166.

Viegas, S. C., Pfeiffer, V., Sittka, A., Silva, I. J., Vogel, J., and Arraiano, C. M. 2007. Characterization of the role of ribonucleases in Salmonella small RNA decay. Nucleic Acids Res. 35:7651-7664.

Yamanaka, K., and Inouye, M. 2001. Selective mRNA degradation by polynucleotide phosphorylase in cold shock adaptation in Escherichia coli. J. Bacteriol. 183:2808-2816.

Yang, C. H., Gavilanes-Ruiz, M., Okinaka, Y., Vedel, R., Berthuy, I., Boccara, M., Chen, J. W., Perna, N. T., and Keen, N. T. 2002. hrp genes of Erwinia chrysanthemi 3937 are important virulence factors. Mol. Plant-Microbe Interact. 15:472-480.

Yang, S., Zhang, Q., Guo, J., Charkowski, A. O., Glick, B. R., Ibekwe, A. M., Cooksey, D. A., and Yang, C. H. 2007. Global effect of indole-3acetic acid biosynthesis on multiple virulence factors of Erwinia chrysanthemi 3937. Appl. Environ. Microbiol. 73:1079-1088.

Yang, S., Peng, Q., San Francisco, M., Wang, Y., Zeng, Q., and Yang, C. H. 2008a. Type III secretion system genes of Dickeya dadantii 3937 are induced by plant phenolic acids. PLoS ONE 3:e2973. Published online.

Yang, S., Peng, Q., Zhang, Q., Yi, X., Choi, C. J., Reedy, R. M., 
Charkowski, A. O., and Yang, C. H. 2008b. Dynamic regulation of GacA in type III secretion, pectinase gene expression, pellicle formation, and pathogenicity of Dickeya dadantii (Erwinia chrysanthemi 3937). Mol. Plant-Microbe Interact. 21:133-142.

Yap, M. N., Yang, C. H., Barak, J. D., Jahn, C. E., and Charkowski, A. O. 2005. The Erwinia chrysanthemi type III secretion system is required for multicellular behavior. J. Bacteriol. 187:639-648.

Ygberg, S. E., Clements, M. O., Rytkonen, A., Thompson, A., Holden, D. W., Hinton, J. C. D., and Rhen, M. 2006. Polynucleotide phosphorylase negatively controls $s p v$ virulence gene expression in Salmonella enterica. Infect. Immun. 74:1243-1254

Zuo, Y., and Deutscher, M. P. 2001. Exoribonuclease superfamilies: Structural analysis and phylogenetic distribution. Nucleic Acids Res. 29:10171026.

\section{AUTHOR-RECOMMENDED INTERNET RESOURCE}

University of Wisconson-Madison ASAP database: asap.ahabs.wisc.edu/asap/ASAP1.htm 